\title{
Oxidative Dehydration of Glycerol over Molybdenum- and Vanadium-Based Catalysts
}

\author{
Franciel A. Bezerra, ${ }^{a}$ Heitor O. N. Altino ${ }^{b}$ and Ricardo R. Soares ${ }^{\circledR *, c}$ \\ ${ }^{a}$ Instituto de Química, Universidade Federal de Uberlândia, \\ Av. João Naves de Ávila, 2121, 38400-902 Uberlândia-MG, Brazil \\ ${ }^{b}$ Departamento de Engenharia Química, Centro Universitário de Patos de Minas (UNIPAM), \\ Rua Major Gote, 808, 38702-054 Patos de Minas-MG, Brazil \\ ${ }^{c}$ Faculdade de Engenharia Química, Universidade Federal de Uberlândia, \\ Av. João Naves de Ávila, 2121, Bloco 1K, 38400-902 Uberlândia-MG, Brazil
}

\begin{abstract}
Surplus of glycerol production from the biodiesel industry has led to the search for glycerol conversion routes, the most common of which are dehydration and oxidative dehydration. Vanadium and molybdenum oxides were supported on $\gamma-\mathrm{Al}_{2} \mathrm{O}_{3}$ and their properties were analyzed through several characterization techniques, showing that the acidity increases after addition of oxides and that in the catalyst with vanadium and molybdenum there is decrease in the band referring to $\mathrm{V}^{5+}$, responsible for sequential oxidation to $\mathrm{CO}_{2}$. The effect of the metal oxides on catalytic activity and stability during oxidative dehydration of glycerol to acrolein was investigated and correlated with chemical composition, acidity, and textural properties. Moreover, the global reaction, turnover frequency (TOF), and activation energy were determined. Catalyst performance and stability were found to depend on acidity and the supported metal with larger residence times (W/F) favored acrolein formation over $\mathrm{CO}_{\mathrm{x}}$. In addition, metal oxides decreased catalyst deactivation via coke oxidation.
\end{abstract}

Keywords: oxidative dehydration of glycerol, molybdenum and vanadium supported oxides, catalytic deactivation

\section{Introduction}

Increasing biodiesel production has resulted in a large surplus of glycerol, since it is coproduced at $10 \mathrm{wt} . \%$ with biodiesel during the transesterification of plant oil or animal fat with methanol. ${ }^{1,2}$ The traditional consumer market of glycerol (cosmetics, tobacco, etc.) is not able to absorb this large amount of product, resulting in a decline in its price. ${ }^{3}$ However, this aqueous, bio-generated glycerol is an attractive compound for chemical synthesis. ${ }^{4}$ Economically, developing alternative processes to glycerol incineration increases the value of biodiesel production and the supply chain of biofuels. ${ }^{2,4}$

Based on its unique structure, including three hydroxyl groups, glycerol can be transformed by various catalytic processes to yield high-value chemicals. Among these catalytic processes, dehydration of glycerol produces acrolein, which is an important chemical intermediate for acrylic acid, acrylic acid esters, superabsorbers, polymers, paints and coatings, and detergents. ${ }^{5,6} \mathrm{It}$ is well known that

*e-mail: rrsoares@ufu.br the type of acid site used plays a key role in dehydration. Weak or medium Brønsted acid sites promote acrolein formation: the hydroxyl of the secondary carbon is protonated, resulting in elimination of a molecule of water and forming 3-hydroxypropanal (3-HPA), a very unstable intermediate that quickly dehydrates to acrolein. On the other hand, dehydration of a terminal hydroxyl by Lewis acid sites results in acetol (Figure 1)..$^{6-8}$

Acidity, catalyst surface area, temperature, and reaction atmosphere affect glycerol dehydration to acrolein. Santos et al. ${ }^{9}$ dehydrated glycerol over ferrierite zeolites and observed that in an oxidizing atmosphere (synthetic air) there is less catalyst deactivation than in an inert atmosphere (helium). This was due to coke elimination by oxygen, which prevented catalyst deactivation. Catalysts with lower acidity also present lower deactivation because there is less coke formation. Kim et al. ${ }^{10}$ compared zeolites (ferrierite, beta, zeolite Socony Mobil-5 (ZSM-5), and Y) with $\gamma-\mathrm{Al}_{2} \mathrm{O}_{3}$ for glycerol dehydration and found that catalysts with lower conversion and selectivity had greater stability. For example, zeolite $\mathrm{H}-$ beta, which had the best initial results, was deactivated by $62 \%$, while $\gamma-\mathrm{Al}_{2} \mathrm{O}_{3}$ was deactivated 


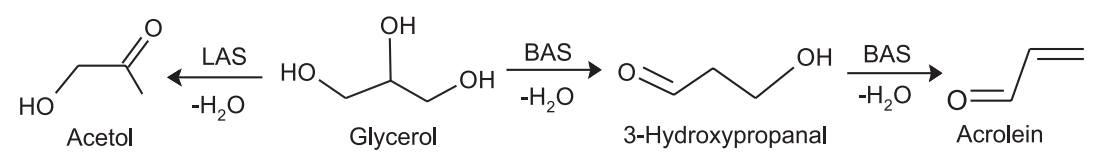

Figure 1. Reaction pathway from glycerol to acrolein and acetol. BAS: Brønsted acid sites; LAS: Lewis acid sites.

by $25 \%$ between 2 and $12 \mathrm{~h}$ of reaction. According to the authors, the surface area influenced conversion, with greater deactivation in zeolites with smaller pores. These results suggest the use of alumina as a support for oxidative glycerol dehydration. Another important factor includes its low price compared with the catalyst used industrially for propylene oxidation, bismuth molybdate $\left(\mathrm{Bi}_{2} \mathrm{Mo}_{3} \mathrm{O}_{12}\right) \cdot{ }^{11}$

The primary catalysts used in glycerol dehydration are deactivated by coke formation at strong acid sites. ${ }^{9}$ Metal oxide addition may therefore improve catalytic activity and stability for acrolein formation by oxidizing coke and regenerating the catalyst surface. Among possible metals, vanadium is promising due to its ability to lose or gain oxygen, resulting in high oxidation power, based on the Mars-van Krevelen mechanism. ${ }^{8}$ There have been several investigations of various materials in the oxidative dehydration of glycerol. Chieregato et al. ${ }^{12}$ described the use of WMoV mixed oxide and the best result was the conversion of $100 \%$ of glycerol into $51 \%$ of selectivity of acrylic acid. Paula et al. ${ }^{13}$ used vanadosilicates and obtained $85.4 \%$ of selectivity of acrylic acid, but with only $1 \mathrm{~h}$ of reaction. The main disadvantages of these materials are the high cost and the difficult preparation process. Thus, stability is a crucial parameter to increase the selectivity to acrylic acid, being the study of the very important, but poorly explored, kinetic properties. ${ }^{11}$

In this study, supported Mo-V oxides were synthesized and assessed for their performance in catalytic oxidative dehydration of glycerol to acrolein. Catalysts were characterized by X-ray diffraction (XRD), energydispersive X-ray spectroscopy (EDS), UV-Vis spectroscopy, $\mathrm{N}_{2}$ physisorption (Brunauer-Emmett-Teller (BET) and Barrett-Joyner-Halenda (BJH) methods), and ammonia and isopropylamine temperature programmed desorption $\left(\mathrm{NH}_{3}-\right.$ and IPA-TPD, respectively). Kinetic parameters were also calculated, including global reaction rate $\left(-r_{\text {glycerol }}\right)$, turnover frequency (TOF), the effect of the residence time (W/F) on materials containing vanadium, and the activation energy of materials containing vanadium-molybdenum.

\section{Experimental}

\section{Catalyst preparation}

Boehmite (AlO $(\mathrm{OH}), \mathrm{G}-250)$ was provided by BASF, while ammonium metavanadate $\left(\mathrm{NH}_{4} \mathrm{VO}_{3}, 99 \%\right)$ and ammonium heptamolybdate $\left(\left(\mathrm{NH}_{4}\right)_{6} \mathrm{Mo}_{7} \mathrm{O}_{24} \cdot 4 \mathrm{H}_{2} \mathrm{O}, 83 \%\right)$ were purchased from Vetec Química Fina and Synth, respectively. Boehmite was calcined in a furnace with an air atmosphere at $823 \mathrm{~K}$ for $4 \mathrm{~h}$, for obtaining $\gamma-\mathrm{Al}_{2} \mathrm{O}_{3}$. The catalysts with $10 \mathrm{wt} . \%$ molybdenum and vanadium loading on $\mathrm{Al}_{2} \mathrm{O}_{3}$ were prepared using incipient wetness impregnation, ${ }^{14}$ also used for preparation of the mixed vanadium and molybdenum catalyst by impregnation of $\mathrm{NH}_{4} \mathrm{VO}_{3}(10 \mathrm{wt} . \%)$ into the catalyst containing molybdenum $\left(\mathrm{Mo} / \gamma-\mathrm{Al}_{2} \mathrm{O}_{3}\right)$. The supported materials were calcined in a furnace with an air atmosphere at $823 \mathrm{~K}$ for $4 \mathrm{~h}$. Alumina and materials containing molybdenum, vanadium, and molybdenum-vanadium are referred to as $\mathrm{Al}, 10 \mathrm{MoAl}$, 10VAl, and 10Mo10VAl, respectively.

\section{Catalyst characterization}

The bulk crystalline structure of catalysts was determined by XRD. XRD patterns were obtained with a Shimadzu XRD-6000 using $\mathrm{Cu} \mathrm{K}_{\alpha}$ radiation $(\lambda=0.15406 \mathrm{~nm})$, operated at voltage and current of $40 \mathrm{kV}$ and $40 \mathrm{~mA}$, respectively. The X-ray analyses were performed using $2 \theta$ angles from 5 to $80^{\circ}$, with step size of $0.04^{\circ}$ and accumulation time of $35 \mathrm{~s}$.

Quantitative EDS was performed using an Oxford INCA X-ACT attached to an electron microscope.

BET surface area was calculated from nitrogen adsorption data at $77 \mathrm{~K}$ obtained using a surface area and porosity analyzer, Micrometrics ASAP 2020, automated gas sorption system. Before measurement, samples were degassed under vacuum at $363 \mathrm{~K}$ for $4 \mathrm{~h}$. The average pore diameter of the catalysts was calculated by the BJH desorption method.

Diffuse reflectance (DR)-UV-Vis spectra were obtained using a UV-2501 (Shimadzu) coupled to an ISR-240A integrating sphere, with $\mathrm{BaSO}_{4}$ as the white standard for alumina and the supports as the white standard for supported materials. Spectra were acquired from 200 to $800 \mathrm{~nm}$.

TPD of ammonia and isopropylamine were used to determine the surface acidities of the catalysts. $\mathrm{NH}_{3}$-TPD (total acid sites) and IPA-TPD (Brønsted acid sites) were conducted in a multifunctional unit coupled to a Pfeiffer mass spectrometer vacuum prism, with 300 and $750 \mathrm{mg}$ of sample, respectively. Samples were pretreated at $573 \mathrm{~K}$ under helium $\left(30 \mathrm{~mL} \mathrm{~min}^{-1}\right)$ for $0.5 \mathrm{~h}$. Saturation with 
$\mathrm{NH}_{3}$ was performed with an $\mathrm{NH}_{3}$ flow $\left(4.84 \% \mathrm{NH}_{3}\right.$ in helium, $30 \mathrm{~mL} \mathrm{~min}^{-1}$ ) at $373 \mathrm{~K}$ for $0.5 \mathrm{~h}$. Samples were then exposed to $\mathrm{He}\left(30 \mathrm{~mL} \mathrm{~min}^{-1}\right.$, at $\left.373 \mathrm{~K}\right)$ for $1 \mathrm{~h}$ to remove the physically adsorbed $\mathrm{NH}_{3}$. Desorption of $\mathrm{NH}_{3}$ was performed in the range $373-973 \mathrm{~K}$ at a heating rate of $10 \mathrm{~K} \mathrm{~min}^{-1}$, with helium flow $\left(30 \mathrm{~mL} \mathrm{~min}^{-1}\right)$. Saturation of isopropylamine was performed using a saturator at $287 \mathrm{~K}$, bubbled with argon $\left(30 \mathrm{~mL} \mathrm{~min}^{-1}\right.$ for $\left.20 \mathrm{~min}\right)$. Then, the samples were held under $30 \mathrm{~mL} \mathrm{~min}^{-1}$ of argon for $0.5 \mathrm{~h}$ for amine desorption. Desorption of amine was performed in the range $323-973 \mathrm{~K}$ at a heating rate of $10 \mathrm{~K} \mathrm{~min}^{-1}$. Masses 44,41 , and 17 were monitored to determine the evolution of isopropylamine, propylene, and ammonia, respectively. The Lewis acid sites were quantified by the difference between the total and Brønsted acid sites. ${ }^{15}$

\section{Reactivity experiments}

Gas-phase oxidative dehydration of glycerol was conducted at atmospheric pressure in a vertical packedbed borosilicate reactor. Prior to the reaction, the catalyst was pretreated at the reaction temperature $(573 \mathrm{~K})$ under helium $\left(1800 \mathrm{~mL} \mathrm{~h}^{-1}\right)$ for $0.5 \mathrm{~h}$. Liquid aqueous glycerol (Vetec Química Fina, 99.5\%, 30 wt.\%) was fed by a highpressure liquid metering pump (Eldex A-10s) at a flow rate of $3 \mathrm{~mL} \mathrm{~h}^{-1}$, together with $2100 \mathrm{~mL} \mathrm{~h}^{-1}$ of synthetic air (White Martins Praxair, 99.9\%). In all experiments, the feed composition was: $4.7 \mathrm{~mol} \%$ glycerol, $7.1 \mathrm{~mol} \% \mathrm{O}_{2}$, $26 \mathrm{~mol} \% \mathrm{~N}_{2}$, and $62.2 \mathrm{~mol} \%$ water; which corresponds to a glycerol: $\mathrm{O}_{2}$ molar ratio of 0.7 . Catalyst masses were varied to ensure $40-60 \%$ glycerol conversion for comparative purposes.

Condensed products were collected in a condenser at $278 \mathrm{~K}$ and analyzed by gas chromatography (Shimadzu GC-2010 Plus) equipped with a capillary column (Rtx-VMS; 30.0 m, 0.25 mm, $1.4 \mu \mathrm{m}$ ). Non-condensed products were analyzed using online gas chromatography (Shimadzu GC-2010 Plus) equipped with a packed column (Heyesep DB 100/120 mesh; 30.0 m, 1.8 mm, 0.85 mm). Glycerol conversion $\left(\mathrm{X}_{\mathrm{gly}}\right)$, selectivity $\left(\mathrm{S}_{\mathrm{i}}\right)$, carbon balance (CB), and $-r_{\text {glycerol }}$ are defined in equations $1-4$, respectively:

$$
\begin{aligned}
& \mathrm{X}_{\mathrm{gly}}(\%)=\frac{\mathrm{n}_{\mathrm{gly}}^{\text {input }}-\mathrm{n}_{\mathrm{gly}}^{\text {output }}}{\mathrm{n}_{\mathrm{gly}}^{\text {input }}} 100 \\
& \mathrm{~S}_{\mathrm{i}}(\%)=\frac{\mathrm{n}_{\mathrm{i}}}{\mathrm{n}_{\mathrm{gly}}^{\text {input }}-\mathrm{n}_{\mathrm{gly}}^{\text {output }}} \frac{\mathrm{Z}_{\mathrm{i}}}{\mathrm{Z}_{\mathrm{gly}}} 100 \\
& \mathrm{CB}(\%)=\frac{\left(\sum \mathrm{n}_{\mathrm{i}} \mathrm{Z}_{\mathrm{i}}\right)+\left(\mathrm{n}_{\mathrm{gly}}^{\text {output }} \mathrm{Z}_{\mathrm{gly}}\right)}{\mathrm{n}_{\text {gly }}^{\text {input }} \mathrm{Z}_{\mathrm{gly}}} 100
\end{aligned}
$$

$-\mathrm{r}_{\text {glycerol }}=\frac{X_{\mathrm{gly}} \mathrm{n}_{\mathrm{gly}}^{\text {input }}}{\mathrm{m}_{\text {cat }}}$

where $\mathrm{n}_{\mathrm{gly}}^{\text {input }}$ and $\mathrm{n}_{\mathrm{gly}}^{\text {output }}$ are the input and output flows of glycerol $\left(\mathrm{mol} \mathrm{min}^{-1}\right), \mathrm{n}_{\mathrm{i}}$ is the flow of the product $\mathrm{i}$ $\left(\mathrm{mol} \mathrm{min}{ }^{-1}\right), \mathrm{Z}_{\mathrm{i}}$ is the number of carbon atoms in product $\mathrm{i}, \mathrm{Z}_{\mathrm{gly}}=3$ is the number of carbons atoms in the glycerol molecule, and $\mathrm{m}_{\text {cat }}$ is the mass of the catalyst $(\mathrm{g})$.

\section{Results and Discussion}

\section{Catalysts characterization}

XRD patterns of vanadium- and molybdenum-based catalysts are shown in Figure 2. The characteristic peaks of $\gamma-\mathrm{Al}_{2} \mathrm{O}_{3}$ are identified at 37.6, 45.8, and 67.0 (Joint Committee on Powder Diffraction Standards (JCPDS) 10-425). ${ }^{16,17}$ Peaks at 25.5, 35.0, 52.5 and $57.5^{\circ}$ are characteristic of $\delta-\mathrm{Al}_{2} \mathrm{O}_{3} \cdot{ }^{15}$ The XRD patterns of supported vanadium and molybdenum oxides (Figures $2 b$ and $2 c$ ) were like that of alumina (Figure 2a), indicating significant dispersion of the oxides at the surface of alumina. ${ }^{16,17} \mathrm{On}$ the other hand, 10Mo10VAl (Figure 2d) showed evidence of formation of monoclinic $\mathrm{MoO}_{3}$, based on the peaks at 13.9, 23.7 and $28.5^{\circ}$ (JCPDS 47-1081). Tetragonal $\mathrm{V}_{2} \mathrm{O}_{5}$ (sharp peaks at 20.0 and $30.0^{\circ}$ (JCPDS 45-1074)) and mixed oxide $\mathrm{V}_{2} \mathrm{MoO}_{8}$ (peaks at 22.0, 25.2, 31.0 and 44.5 (JCPDS 18-0851)) ${ }^{16}$ were observed (Figure 2d) resulting from the greater presence of oxide at the surface of alumina. The crystallites size, obtained by the Scherrer equation, are shown in Table 1. There was slight increase in the crystallite size adding molybdenum and vanadium oxides, while in the material with mixed oxides there was an increase of about eight times due to the presence of crystalline phases on the surface. These results show that the catalyst remains amorphous after the addition of vanadium or molybdenum oxide, while in the mixed material $\mathrm{MoO}_{3}$ crystals are formed.

Figure 3 shows the DR-UV-Vis spectra of the calcined catalysts, with their respective white standard in parentheses. Pure alumina showed no absorption in the UV region, while $10 \mathrm{MoAl}$ exhibited strong absorption bands, with a band at $225 \mathrm{~nm}$ attributed to the ligand to metal charge transfer (LMCT) band of $\mathrm{O}^{2-} \rightarrow \mathrm{Mo}^{6+}$, in good agreement with tetrahedral molybdate species and the $300 \mathrm{~nm}$ band assigned to the octahedral molybdate species. ${ }^{18,19}$ For the 10VAl surface, tetrahedrally coordinated vanadium exhibited UV bands at 240 and $300 \mathrm{~nm}$, assigned to charge-transfer transitions involving oxygen and vanadium in tetrahedral coordination, present as isolated species. ${ }^{17,18,20,21}$ The $375 \mathrm{~nm}$ band can be attributed to 
Table 1. Characteristics of molybdenum and vanadium supported catalysts

\begin{tabular}{lccccccc}
\hline Catalyst & $\begin{array}{c}\text { Crystallite } \\
\text { size / } \mathrm{nm}\end{array}$ & Metal loading / \% & $\mathrm{S}_{\mathrm{BET}} /\left(\mathrm{m}^{2} \mathrm{~g}^{-1}\right)$ & Pore size / nm & $\begin{array}{c}\text { Total acid site / } \\
\left(\mu \mathrm{mol} \mathrm{NH}_{3} \mathrm{~g}^{-1}\right)\end{array}$ & $\begin{array}{c}\text { Brønsted acid } \\
\text { site } /(\mu \mathrm{mol} \mathrm{g})\end{array}$ & $\begin{array}{c}\text { Brønsted/Lewis } \\
\text { ratio }\end{array}$ \\
\hline $\mathrm{Al}$ & 4.64 & - & 130.0 & 12.3 & 101.8 & 55.8 & 1.21 \\
$10 \mathrm{MoAl}$ & 4.90 & 9.1 & 162.4 & 10.1 & 304.8 & 61.3 & 0.25 \\
$10 \mathrm{VAl}$ & 5.71 & 10.1 & 112.3 & 11.2 & 372.1 & 97.7 & 0.36 \\
10Mo10VAl & 37.34 & $9.6 ; 10.3$ & 83.8 & 12.5 & 232.9 & 80.3 & 0.53 \\
\hline
\end{tabular}

$\mathrm{S}_{\mathrm{BET}}$ : specific surface area calculated using the Brunauer-Emmett-Teller method; Al: alumina; 10MoAl, 10VAl, 10Mo10VAl: catalysts containing molybdenum, vanadium, and molybdenum-vanadium, respectively.

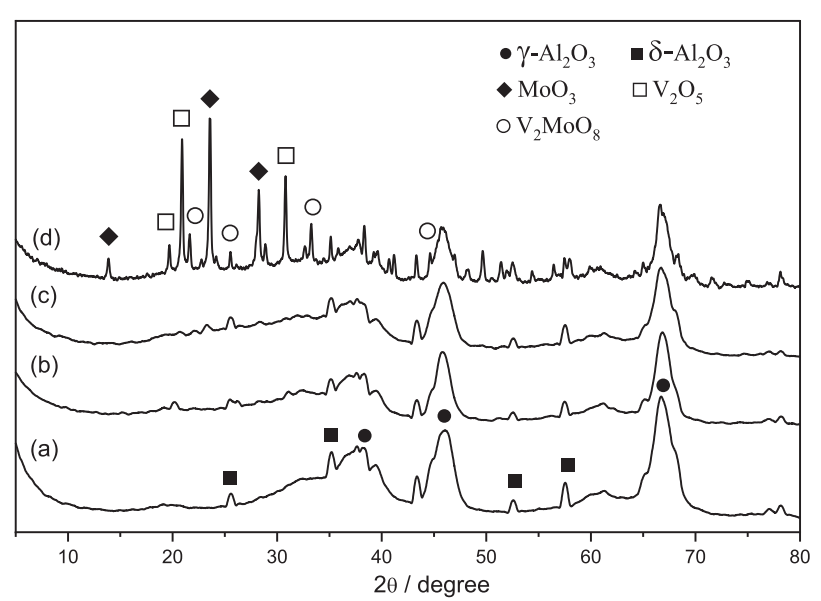

Figure 2. XRD pattern of catalysts: (a) $\mathrm{Al}$; (b) 10MoAl; (c) 10VAl; and (d) 10Mo10Val.

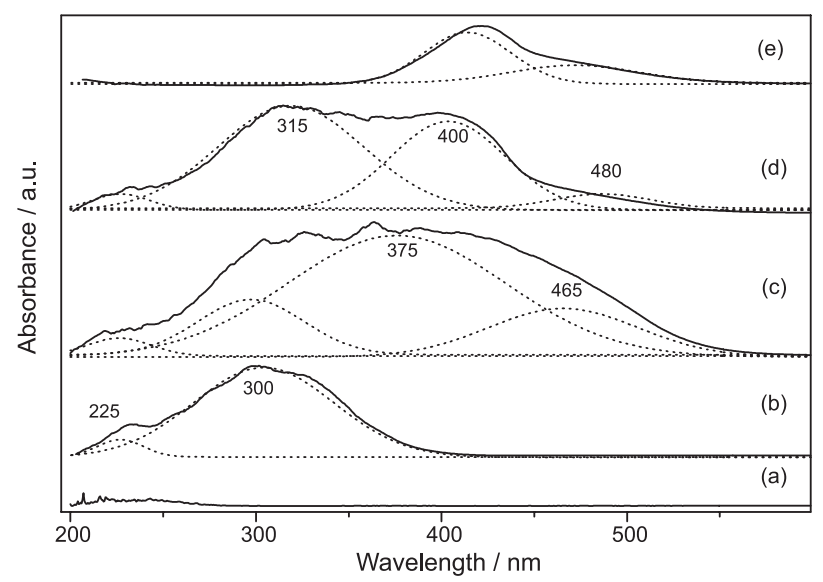

Figure 3. DR-UV-Vis spectra of catalysts: (a) $\mathrm{Al}\left(\mathrm{BaSO}_{4}\right)$; (b) $10 \mathrm{MoAl}$ (Al); (c) 10VAl (Al); (d) 10VMoAl (Al); and (e) 10VMoAl (10MoAl).

isolated octahedrally coordinated $\mathrm{V}^{5+}$, and the $480 \mathrm{~nm}$ band can be attributed to octahedral $\mathrm{VO}_{6}$ chains from welldispersed or crystalline $\mathrm{V}_{2} \mathrm{O}_{5}$ clusters. ${ }^{18,21}$ The main change caused by the insertion of vanadium in $10 \mathrm{MoAl}$ (Figure $3 \mathrm{~d}$ ) was in the decrease in the polymer species of $\mathrm{V}_{2} \mathrm{O}_{5}$ (bands between 400 and $500 \mathrm{~nm}$ ), indicating that molybdenum acts by reducing $\mathrm{V}^{5+}$ ions. ${ }^{20}$

Elemental analysis, surface area, and pore size are presented in Table 1. The metal percentages were in agreement with nominal values chosen for impregnation. Homogeneity was confirmed by analysis at different sample points. The addition of vanadium and molybdenum oxides decreased the surface area and pore size, except for $10 \mathrm{MoAl}$ and 10Mo10VAl, where the surface area and pore size were respectively increased. This decrease in the surface area was ascribed to filling of mesopores of the support by addition of metal oxide. ${ }^{17}$ The larger surface area of $10 \mathrm{MoAl}$ may be attributed to stronger interaction of Mo with the alumina surface even in the narrowest pores, thus preventing the Mo species from agglomerating in these pores. ${ }^{22}$

The total and Brønsted acidities were determined by $\mathrm{NH}_{3}$-TPD and IPA-TPD, respectively. Desorption profiles of ammonia showed a large increase in total acidity after addition of metal oxides, in the range 423$873 \mathrm{~K}$ for all materials (Figure $4 \mathrm{a}$ ). Figure $4 \mathrm{~b}$ shows propylene desorption from degradation of isopropylamine in propylene and $\mathrm{NH}_{3}$ at the Brønsted acid sites. Alumina presents a distinct profile compared to the supported materials, with three mass losses, the greatest of which is at $800 \mathrm{~K}$. The supported material presented desorption at lower temperatures, indicating that they have Brønsted sites of weak and medium strength, which are more suitable for formation of acrolein.

The quantification of acid sites is presented in Table 1. The presence of metal oxides increased the number of Lewis acid sites with a slight increase in the number of Brønsted sites. The increase is explained by the capacity of vanadium and molybdenum to present variable oxidation states, promoting the transfer of electrons, which is a characteristic of Lewis acid sites. ${ }^{13}$ Because vanadium has a greater capacity to vary its oxidation state, 10VAl exhibits higher acidity. On the other hand, 10Mo10VAl shows lower acidity, which can be justified by the UV-Vis results. According to Wachs, ${ }^{23}$ most low-valent oxides typically exhibit only surface Lewis acidity and most high-valent oxides typically contain both surface Lewis and Brønsted acidity, which explains the decrease in Brønsted acidity, since the UV-Vis results showed that there was a decrease in $\mathrm{V}^{5+}$ species. On the other hand, the 


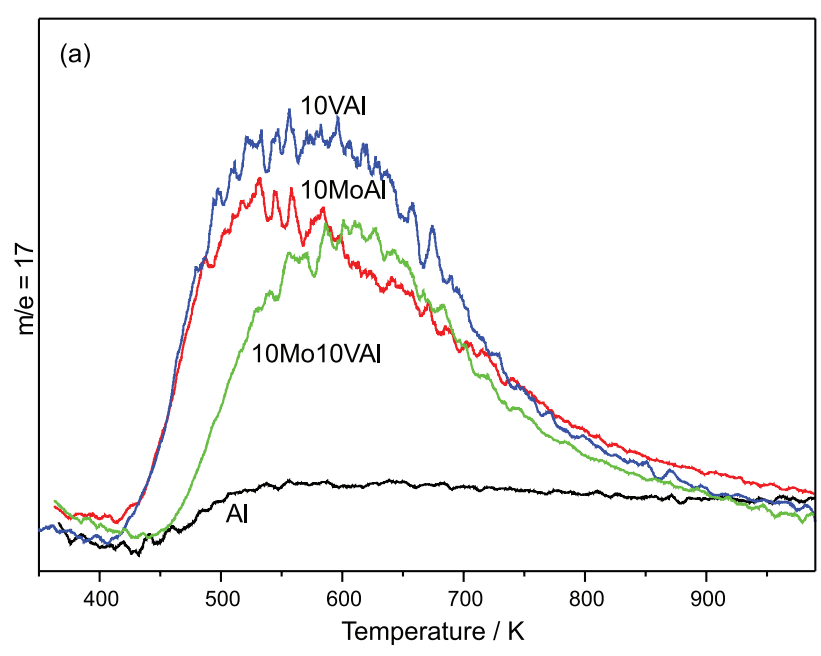

Figure 4. TPD profiles of (a) adsorbed ammonia and (b) propylene.

decrease in total acidity is a consequence of the smaller specific surface area. ${ }^{24}$

\section{Catalytic activity}

Glycerol and $\mathrm{O}_{2}$ conversion are shown in Figure 5. The low glycerol conversion in the reaction without catalyst shows that at this temperature there is virtually no reaction. The catalysts were deactivated to different degrees, in the following order: $10 \mathrm{MoAl}(60 \%)>10 \mathrm{Mo} 10 \mathrm{VAl}$ $(40 \%)>\mathrm{Al}(30 \%)>10 \mathrm{VAl}(17 \%)$, with different times for stabilization. The profiles of $\mathrm{O}_{2}$ conversion were similar, but as expected, in the reaction with alumina the consumption was lower than that of materials containing supported metal oxides, since the oxides are responsible for dissociation and oxidation with the $\mathrm{O}_{2}$ molecule. The molar ratio of glycerol: $\mathrm{O}_{2}$ consumption was: $\mathrm{Al}=4: 1$, $10 \mathrm{MoAl}=1: 1,10 \mathrm{VAl}=1: 1.5$, and $10 \mathrm{Mo} 10 \mathrm{VAl}=1: 1.8$. Materials with higher consumption of $\mathrm{O}_{2}$ presented lower deactivation, suggesting that $\mathrm{O}_{2}$ promotes degradation of

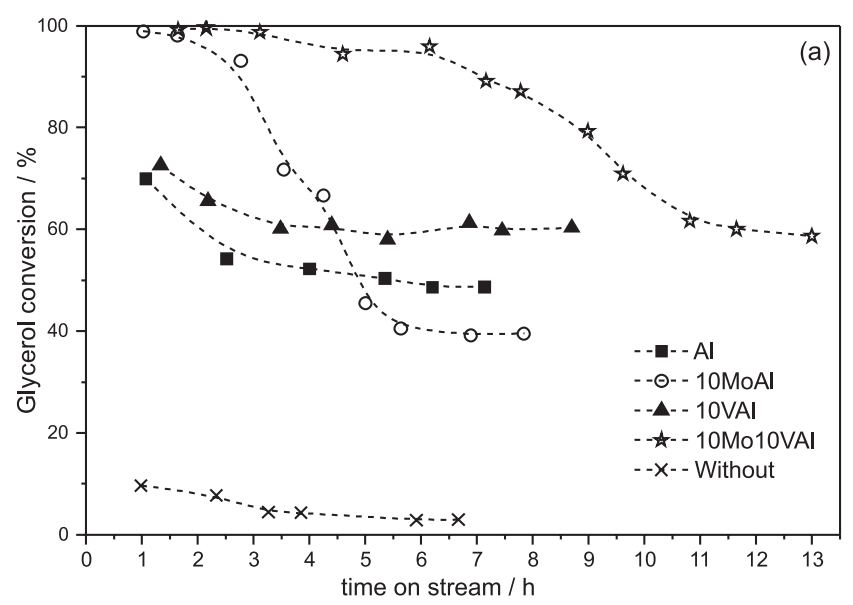

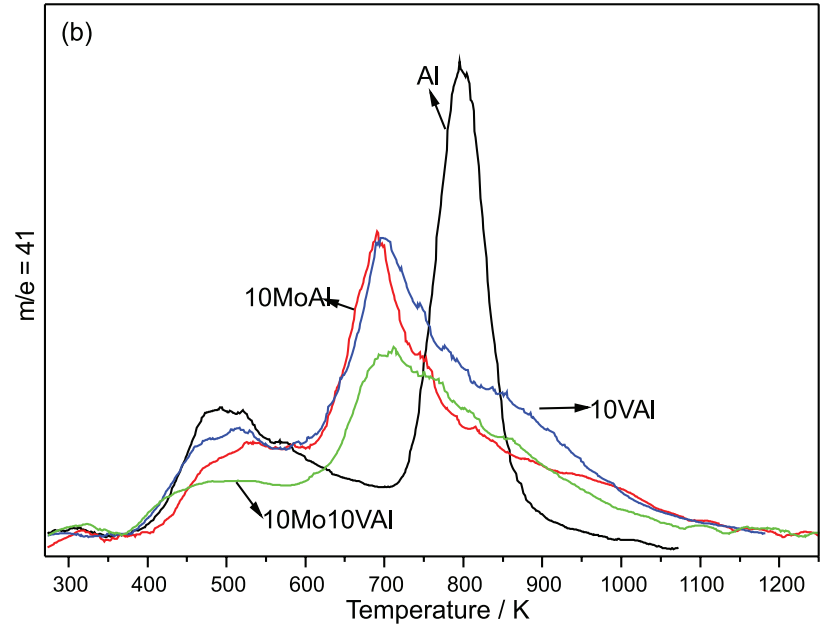

the coke formed in the reaction and the complete oxidation of intermediates before their condensation, which causes deactivation through surface obstruction.

Catalyst deactivation because of coke deposition on catalyst surfaces is the main obstacle for industrial application of the synthesized catalysts in green chemistry. ${ }^{11}$ The presence of vanadium oxide on the alumina surface decreased deactivation, while molybdenum increased deactivation. Vanadium may regenerate the catalyst surface by coke oxidation via the Mars-van Krevelen redox cycle, ${ }^{25-27}$ in which the mobile lattice oxygen of vanadium oxide reacts with coke to form $\mathrm{CO}$ and $\mathrm{CO}_{2}$; oxygen from the feed then regenerates the oxide.

The selectivity of products with catalysts is shown in Table 2. Using alumina, the main products were acrolein and acetol, with 27.9 and $15.0 \%$ yield, respectively, because of the Brønsted and Lewis acid sites. Other products were obtained in low quantity. This result agrees with the similar number of Brønsted and Lewis acid sites. However, due to the greater activity of Brønsted sites, which require a

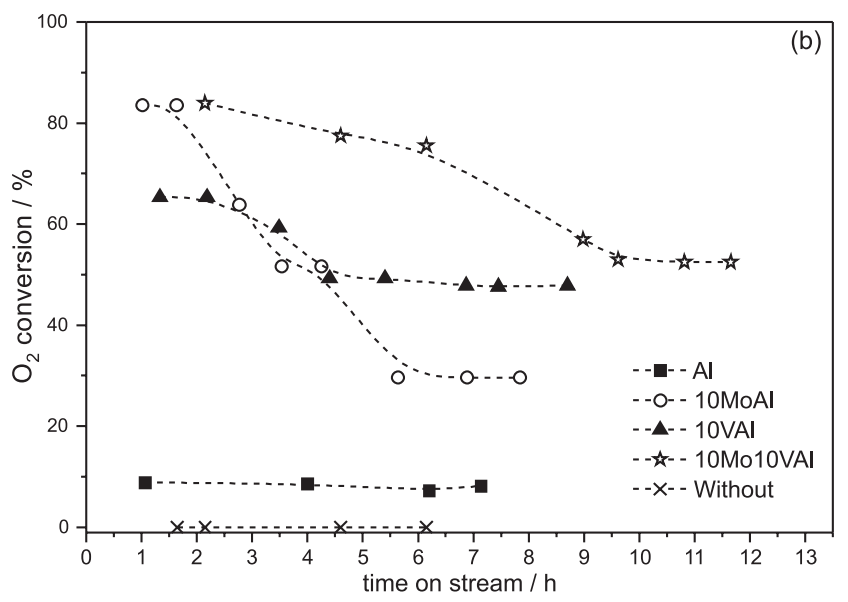

Figure 5. (a) Glycerol and (b) $\mathrm{O}_{2}$ conversion with time on stream (TOS). 
Table 2. Selectivity of products of oxidative dehydration ${ }^{\mathrm{a}}$ as a function of catalyst

\begin{tabular}{|c|c|c|c|c|c|}
\hline Catalyst & & $\mathrm{Al}$ & $10 \mathrm{MoAl}$ & 10VAl & 10Mo10VA \\
\hline $\mathrm{X}_{\mathrm{gly}} / \%$ & & 53 & 40 & 60 & 60 \\
\hline $\mathrm{X}_{\mathrm{O} 2} / \%$ & & 8.6 & 29 & 47.8 & 52.9 \\
\hline \multirow[t]{12}{*}{$\mathrm{S}_{\mathrm{i}} / \%$} & acrolein & 27.9 & 41.2 & 36.3 & 26.1 \\
\hline & acetol & 15.0 & 1.1 & 0.6 & 0.7 \\
\hline & acetaldehyde & 0.4 & 2.4 & 4.1 & 3.1 \\
\hline & pyruvaldehyde & 5.5 & 9.6 & 4.0 & 4.6 \\
\hline & acetic acid & 0.4 & 1.9 & 3.7 & 3.7 \\
\hline & acrylic acid & 1.2 & 0.9 & 0.5 & 2.0 \\
\hline & glycerol formal & 2.4 & 7.3 & 1.2 & 3.7 \\
\hline & 1,2-propanediol & 1.2 & 0.0 & 0.0 & 0.0 \\
\hline & methanol & 1.0 & 0.0 & 0.2 & 0.0 \\
\hline & allyl alcohol & 1.4 & 0.4 & 0.6 & 0.4 \\
\hline & $\mathrm{CO}$ & 6.0 & 9.9 & 15.8 & 17.1 \\
\hline & $\mathrm{CO}_{2}$ & 2.4 & 13.9 & 12.8 & 12.5 \\
\hline $\mathrm{CB} / \%$ & & 81.6 & 95.4 & 90.5 & 87.5 \\
\hline $\mathrm{W} / \mathrm{F} / \mathrm{s}$ & & 1087 & 813 & 166 & 680 \\
\hline
\end{tabular}

aReaction conditions: atmospheric pressure, $573 \mathrm{~K}$, feed molar ratio of glycerol/ $\mathrm{O}_{2} / \mathrm{N}_{2} / \mathrm{H}_{2} \mathrm{O}$ of 4.7:7.1:26:62.2. Al: alumina; 10MoAl, 10VAl, 10Mo10VAl: catalysts containing molybdenum, vanadium, and molybdenum-vanadium, respectively; $\mathrm{X}_{\mathrm{gly}}$ : glycerol conversion; $\mathrm{X}_{\mathrm{O} 2}$ : $\mathrm{O}_{2}$ conversion; $\mathrm{S}_{\mathrm{i}}$ : selectivity; CB: carbon balance; W/F: residence time.

lower temperature than Lewis acid sites, double amount of acrolein was produced. ${ }^{28}$ However, alumina needed longer residence time to achieve conversion in this study range, confirming that its catalytic activity is much lower than the supported oxide catalysts.

$10 \mathrm{MoAl}$ presented the highest selectivity for acrolein, with two other products with relevant selectivity also formed: pyruvaldehyde $(9.6 \%)$ and glycerol formal (7.3\%). Pyruvaldehyde can be obtained through acetol dehydrogenation, since the formation of coke facilitates the transfer of hydrogen in dehydration products, ${ }^{14}$ explaining the low selectivity for acetol. On the other hand, glycerol formal is a characteristic product of condensation of glycerol with formaldehyde, resulting from glycerol degradation in formaldehyde and acetaldehyde with a molecule of glycerol. Although $10 \mathrm{MoAl}$ had the highest selectivity for acrolein, it also needed more residence time to achieve conversion compared to materials containing vanadium, which demonstrates the lower catalytic performance of molybdenum.

The catalysts containing vanadium, 10VAl and 10Mo10VAl, were the most active, requiring less residence time, even presenting the smallest specific surface areas (Table 1). These materials showed greater selectivity for acetaldehyde and $\mathrm{CO}$, resulting from the decarbonization of acetol and incomplete carbonization. ${ }^{14,29}$ They were also more selective for acrylic and acetic acid, confirming the higher oxidative capacity of vanadium. The low selectivity of acetol and acetaldehyde is explained by the reaction temperature. Although the materials had a greater number of Lewis acid sites, they require a higher temperature for activation compared to Brønsted acid sites..$^{25}$ Moreover, the presence of vanadium favors the formation of acrylic acid and acetic acid by partial oxidation of acrolein and acetaldehyde, respectively.

Although the materials presented a greater number of Lewis acid sites, the greater formation of acrolein than acetol can be explained by: (i) the cooperative effect between the Brønsted and Lewis sites; and (ii) the conversion of Lewis acid sites to Brønsted acid sites in the presence of steam. ${ }^{6,30-32}$ Wang et al..$^{32}$ proposed that Brønsted acid sites initiate the first-step dehydration of the secondary hydroxyl group of glycerol, and the neighboring Lewis acid sites collaborated to complete the second-step dehydration of the primary hydroxyl groups to form acrolein.

The effect of W/F was studied with materials containing vanadium, which showed lower deactivation (Figure 6). For both materials, conversion and acrolein selectivity increased when $\mathrm{W} / \mathrm{F}$ was increased, while $\mathrm{CO}_{\mathrm{x}}$ selectivity presented a distinct behavior between the materials with variations in W/F. The greatest acrolein selectivity was obtained with 10Mo10VAl (75\% selectivity for $87 \%$ of conversion), while for 10VAl with the same W/F, the selectivity was $52 \%$ with $86 \%$ of conversion. 

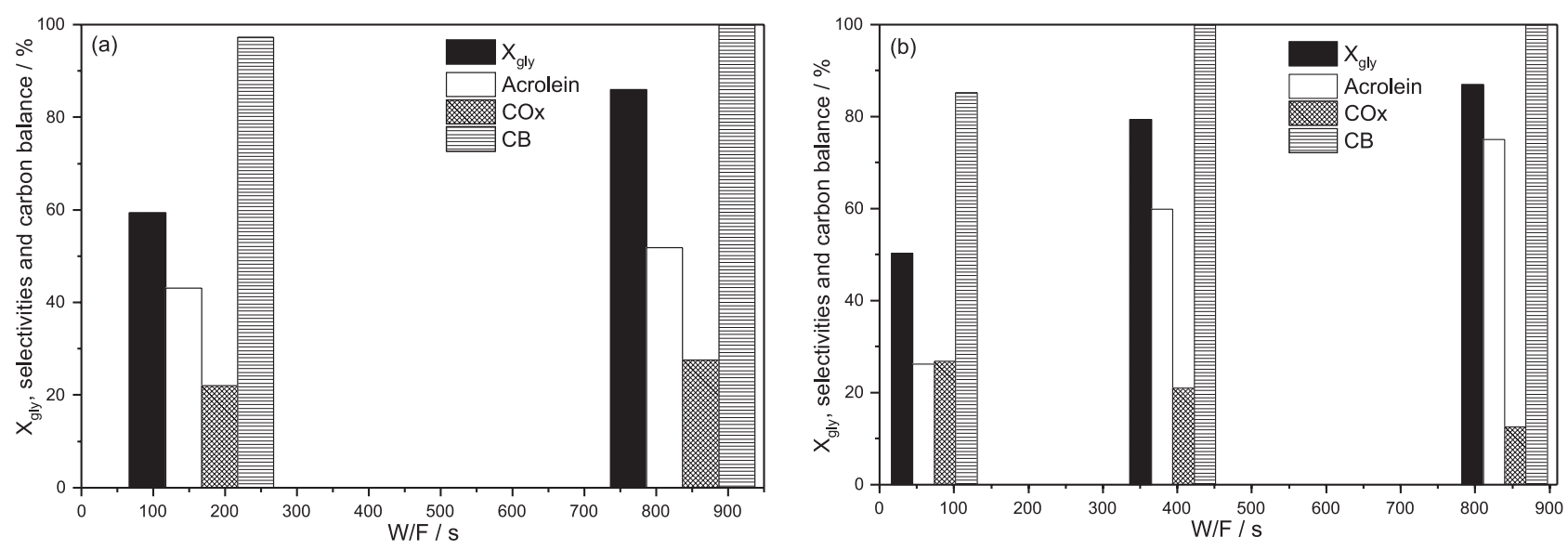

Figure 6. Glycerol conversion $\left(\mathrm{X}_{\mathrm{gly}}\right)$, acrolein and $\mathrm{CO}_{\mathrm{x}}$ selectivity, and carbon balance $(\mathrm{CB})$ as a function of W/F over (a) $10 \mathrm{VAl}$ and (b) $10 \mathrm{Mo10VAl}$.

Table 3. Kinetic properties for the oxidative dehydration of glycerol with vanadium and molybdenum oxides supported on $\gamma-\mathrm{Al}_{2} \mathrm{O}$

\begin{tabular}{|c|c|c|c|c|}
\hline Catalyst & $-\mathrm{r}_{\text {glycerol }}$ a $/\left(\mathrm{mmol}_{\text {glycerol }} \mathrm{g}_{\text {cat }}{ }^{-1} \mathrm{~s}^{-1}\right)$ & $\mathrm{TOF}_{\text {glycerol }}(\mathrm{TAS}) / \mathrm{s}^{-1}$ & $\mathrm{TOF}_{\text {glycerol }}(\mathrm{BAS}) / \mathrm{s}^{-1}$ & $\mathrm{Ea} /\left(\mathrm{kJ} \mathrm{mol}^{-1}\right)$ \\
\hline $\mathrm{Al}$ & 0.013 & 2.128 & 3.883 & \\
\hline $10 \mathrm{MoAl}$ & $0.069(0.76)$ & 3.773 & 18.760 & \\
\hline 10VAl & $0.043(0.42)$ & 1.926 & 7.335 & \\
\hline 10Mo10VAl (548 K) & 0.074 & 5.296 & 15.359 & 57.10 \\
\hline 10Mo10VAl (573 K) & $0.092(0.46)$ & 6.584 & 19.095 & \\
\hline 10Mo10VAl (598 K) & 0.205 & 14.670 & 42.549 & \\
\hline
\end{tabular}

${ }^{a}$ Data in parentheses correspond to the rate per mass of metal (EDS). $-\mathrm{r}_{\text {glycerol }}$ : global reaction rate; $\mathrm{g}_{\text {cat }}$ : mass of catalyst, in g; TOF: turnover frequency; Ea: activation energy; TAS: total acid sites ( $\left.\mathrm{mmol} \mathrm{g}_{\mathrm{cat}}{ }^{-1}\right)$; BAS: Brønsted acid sites ( $\left.\mathrm{mmol} \mathrm{g}_{\text {cat }}{ }^{-1}\right)$; $\operatorname{TOF}_{\text {glycerol }}(\mathrm{TAS})$ and $\mathrm{TOF}_{\text {glycerol }}(\mathrm{BAS})$ : $\mathrm{TOF}_{\text {glycerol }} \mathrm{calculated}$ considering TAS and BAS, respectively; Al: alumina; 10MoAl, 10VAl, 10Mo10VAl: catalysts containing molybdenum, vanadium, and molybdenumvanadium, respectively.

Low conversion (less than $25 \%$ ) was observed at $573 \mathrm{~K}$, and TOF for total acid sites and Brønsted acid sites was calculated for all catalysts (Table 3). The order of the reaction rates obtained were: $\mathrm{Al}<10 \mathrm{VAl}<10 \mathrm{MoAl}<$ $10 \mathrm{Mo10VAl}$, showing that the rate increases with the increase of acidity, from Al to 10Mo10VAl, however, it is lower for those with higher total acidity, 10VAl and 10MoAl. On the other hand, the TOF for total acid sites were: $10 \mathrm{VAl}<\mathrm{Al}<10 \mathrm{MoAl}<10 \mathrm{Mo} 10 \mathrm{VAl}$; and the TOF for Brønsted acid sites were: $\mathrm{Al}<10 \mathrm{VAl}<10 \mathrm{Mo} 10 \mathrm{VAl}<$ $10 \mathrm{MoAl}$. With exception of bimetallic material, it was observed that the TOF increases as surface area increases, according to the greater activity expected for materials with greater area available to convert glycerol. ${ }^{33}$ When analyzing only the effect of Brønsted acid sites in the TOF, the cooperative effect between the Brønsted and Lewis sites in the acrolein formation is confirmed, since $10 \mathrm{MoAl}$, even with the smallest quantity of Brønsted acid sites between supported materials, has the highest selectivity to acrolein, indicating that not only the Brønsted sites act in the acrolein formation.

Based on this, reaction temperature was varied (548, 573 and $598 \mathrm{~K}$ ) with the same mass of catalyst 10Mo10VAl.
As expected, an increase in reaction temperature resulted in increased reaction rates. From the intersection of the natural logarithm of the reaction rate with 1 / T $(\mathrm{K})$, the apparent activation energy was calculated (Figure 7). The value obtained $\left(57.1 \mathrm{~kJ} \mathrm{~mol}^{-1}\right)$ agrees with the value obtained by Talebian-Kiakalaieh and Amin, ${ }^{33}$ who performed the glycerol dehydration using $\mathrm{HSiW}-\gamma-\mathrm{Al}_{2} \mathrm{O}_{3}$ supported

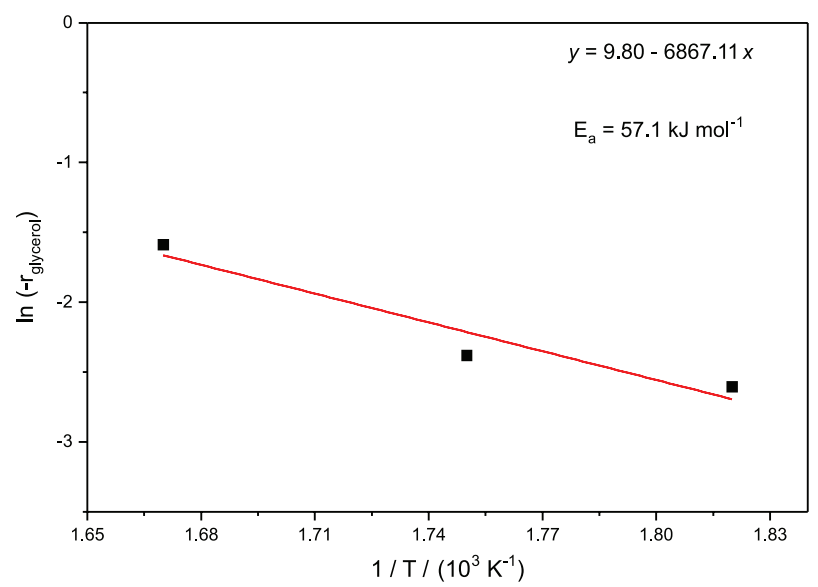

Figure 7. Linearization of the Arrhenius equation for the catalyst 10Mo10VAl. Reaction conditions: catalyst mass of $0.0153 \mathrm{~g}$ and feed molar ratio of glycerol $/ \mathrm{O}_{2} / \mathrm{N}_{2} / \mathrm{H}_{2} \mathrm{O}$ of 4.7:7.1:26:62.2. 
in $\mathrm{ZrO}_{2}$ and measured a global activation energy of $46.9 \mathrm{~kJ} \mathrm{~mol}^{-1}$. Moreover, the value measured here is much lower than that obtained by Ott et al. ${ }^{34}$ who performed the reaction with zinc sulfate in supercritical conditions $\left(140 \pm 12 \mathrm{~kJ} \mathrm{~mol}^{-1}\right)$, highlighting the catalyst efficiency.

\section{Conclusions}

Vanadium and molybdenum oxides supported in alumina were investigated for the oxidative dehydration of glycerol to acrylic acid. XRD spectra showed that the metal oxides are well dispersed in 10MoAl and 10VAl, since only diffraction peaks of alumina are observed, while for the mixed material, 10Mo10VAl, are observed peaks of $\mathrm{V}_{2} \mathrm{O}_{5}, \mathrm{MoO}_{3}$ and $\mathrm{V}_{2} \mathrm{MoO}_{8}$. The UV-Vis analyses show the presence of tetrahedral and octahedral vanadium and molybdenum and that in the mixed material there was a decrease of the band in $375 \mathrm{~nm}$ relative to $\mathrm{V}^{5+}$, which favors the sequential oxidation to $\mathrm{CO}_{2}$, consequently favoring the partial oxidation of acrolein to acrylic acid. $\mathrm{N}_{2}$ physisorption, and $\mathrm{NH}_{3}$ - and IPA-TPD showed a decrease in surface due to overcoating by oxides and an increase in Lewis acidity, which is characteristic of metal oxides.

Materials containing vanadium had lower deactivation, indicating that vanadium promotes coke oxidation by the Mars-van Krevelen mechanism, recovering catalytic activity; moreover, they have the highest selectivity to acrylic and acetic acids, confirming the potential of vanadium to partial oxidation. On the other hand, $10 \mathrm{MoAl}$, even with the highest selectivity to acrolein, has a very high deactivation of $60 \%$. The effect of residence time was studied with 10VAl and 10Mo10VAl, achieving greater acrolein selectivity $(75 \%)$ with low $\mathrm{CO}_{\mathrm{x}}$ formation $(8 \%)$ at high residence times. 10Mo10VAl exhibited the highest reaction rate and had an activation energy of $57.1 \mathrm{~kJ} \mathrm{~mol}^{-1}$, consistent with literature results.

\section{Acknowledgments}

We would like to acknowledge CAPES for a scholarship (F. A. B.) and FAPEMIG for the financial support.

\section{References}

1. Ciriminna, R.; Pina, C. D.; Rossi, M.; Pagliaro, M.; Eur. J. Lipid Sci. Technol. 2014, 116, 1432.

2. Li, X.; Zhang, Y.; ACS Catal. 2016, 6, 2785.

3. Katryniok, B.; Paul, S.; Dumeignil, F.; ACS Catal. 2013, 3, 1819.

4. Danov, S.; Esipovich, A.; Belousov, A.; Rogozhin, A.; Chin. J. Chem. Eng. 2015, 23, 1138.
5. Kim, Y. T.; Jung, K. D.; Park, E. D.; Microporous Mesoporous Mater. 2010, 131, 28.

6. Talebian-Kiakalaieh, A.; Amin, N. A. S.; Hezaveh, H.; Renewable Sustainable Energy Rev. 2014, 40, 28.

7. Yun, D.; Yun, Y. S.; Kim, T. Y.; Park, H.; Lee, J. M.; Han, J. W.; Yi, J.; J. Catal. 2016, 341, 33.

8. Possato, L. G.; Chaves, T. F.; Cassinelli, W. H.; Pulcinelli, S. H.; Santilli, C. V.; Martins, L.; Catal. Today 2017, 289, 20.

9. Santos, M. B.; Andrade, H. M. C.; Mascarenhas, A. J. S.; Microporous Mesoporous Mater. 2016, 223, 106.

10. Kim, Y. T.; Jung, K. D.; Park, E. D.; Appl. Catal., A 2011, 393, 275.

11. Talebian-Kiakalaieh, A.; Amin, N. A. S.; Renewable Energy 2017, 114, 794.

12. Chieregato, A.; Soriando, M. D.; García-González, E.; Puglia, G.; Basile, F.; Concepción, P.; Bandinelli, C.; Lopéz Nieto, J. M.; Cavani, F.; ChemSusChem 2014, 8, 398.

13. Paula, A. S.; Possato, L. G.; Ratero, D. R.; Contro, J.; Keinan-Adamsky, K.; Soares, R. R.; Goobes, G.; Martins, L.; Microporous Mesoporous Mater. 2016, 232, 151.

14. Witsuthammakul, A.; Sooknoi, T.; Appl. Catal., A 2012, 413, 109.

15. Kim, J.; Lee, D.; Int. J. Hydrogen Energy 2013, 38, 11853.

16. Meng, Y.; Wang, T.; Chen, S.; Zhao, Y.; Ma, X.; Gong, J.; Appl. Catal., B 2014, 160-161, 161.

17. Renuka, N. K.; Shijina, A. V.; Praveen, A. K.; Mater. Lett. 2013 , $113,96$.

18. Mitran, G.; Pavel, O. D.; Marcu, I. C.; J. Mol. Catal. A: Chem. 2013, 370, 104.

19. Høj, M.; Kessler, T.; Beato, P.; Jensen, A. D.; Grunwaldt, J.; Appl. Catal., A 2014, 472, 29.

20. Concepcion, P.; Navarro, M. T.; Blasco, T.; López Nieto, J. M.; Panzacchi, B.; Rey, F.; Catal. Today 2004, 96, 179.

21. Held, A.; Kowalska-Kus, J.; Nowinska, K.; Catal. Commun. 2012, 17, 108.

22. Mathew, S.; Kathyayini, H.; Nagy, J. B.; Nagaraju, N.; Catal. Commun. 2009, 10, 1043.

23. Wachs, I. E.; Catal. Today 2005, 100, 79.

24. Hu, P.; Lang, W.; Yan, X.; Chen, X.; Guo, Y.; Appl. Catal., A 2018, 553, 65 .

25. Possato, L. G.; Cassinelli, W. H.; Garetto, T.; Pulcinelli, S. H.; Santilli, C. V.; Martins, L.; Appl. Catal., A 2015, 459, 243.

26. Chieregato, A.; Lopez Nieto, J. M.; Cavani, F.; Coord. Chem. Rev. 2015, 301-302, 3.

27. Deleplanque, J.; Dubois, J.-L.; Devaux, J.-F.; Ueda, W.; Catal. Today 2010, 157, 351.

28. Alhanash, A.; Kozhevnikova, E. F.; Kozhevnikov, I. V.; Appl. Catal., A 2010, 378, 11.

29. Liu, R.; Wang, T.; Cai, D.; Jin, Y.; Ind. Eng. Chem. Res. 2014, 53,8667 . 
30. Foo, G. S.; Wei, D.; Sholl, D. S.; Sievers, C.; ACS Catal. 2014, 4, 3180 .

31. García-Sancho, C.; Cecilia, J. A.; Moreno-Ruiz, A.; MéridaRobles, J. M.; Santamaría-González, J.; Moreno-Tost, R.; Meireles-Torres, P.; Appl. Catal., B 2015, 179, 139.

32. Wang, Z.; Wang, L.; Jiang, Y.; Hunger, M.; Huang, J.; ACS Catal. 2014, 4, 1144.
33. Talebian-Kiakalaieh, A.; Amin, N. A. S.; J. Taiwan Inst. Chem. Eng. 2016, 59, 11.

34. Ott, L.; Bicker, M.; Vogel, H.; Green Chem. 2006, 8, 214.

Submitted: July 24, 2018

Published online: December 20, 2018 